\title{
Fibroblast Growth Factor Receptor 4 Gly388Arg Gene Polymorphism and Non-Hodgkin Lymphoma Susceptibility and Prognosis in Egyptian population: Case-control Study
}

\author{
Wafaa M. Abdelghany ${ }^{1 *}$, Shahira Kamal Anis Botros ${ }^{1}$, Osman Mohamed Mansour ${ }^{2}$, Mahmoud A. Ayoub $^{3}$, \\ Abdallah M. Almuslimani ${ }^{3}$, Naglaa M. Hassan ${ }^{3}$ \\ ${ }^{1}$ Department of Clinical and Chemical Pathology, Faculty of Medicine, Cairo University, Cairo, Egypt; ${ }^{2}$ Department of Medical \\ Oncology, National Cancer Institute, Cairo University, Cairo, Egypt; ${ }^{3}$ Department of Clinical and Chemical Pathology, National \\ Cancer Institute, Cairo University, Cairo, Egypt
}



\begin{abstract}
BACKGROUND: Angiogenesis is a multistep process having an essential role in the growth and progression of various tumors including hematolymphoid malignancies. Basic fibroblast growth factor (bFGF) is one of angiogenic growth factors which level is considered as prognostic factor in lymphoma and leukemia. It mediates its action by binding to high affinity cell surface receptors-fibroblast growth factor receptor 1-4 (FGFR4) with receptor kinase activity. Therefore, upregulation of BFGF-FGFR system may cause increased risk of non-Hodgkin lymphomas (NHLs).

AIM: Our study aimed to determine the association between the FGFR4 Gly388Arg (rs351855G/A) polymorphism and NHL disease susceptibility and prognosis.

MATERIALS AND METHODS: The present study included 75 NHL patients and 100 healthy controls. Genotyping of FGFR4 was done by Polymerase Chain Reaction-Restriction Fragment Length polymorphism (PCR-RFLP). As after the amplification of the target gene, the PCR products were digested with BstNI restriction endonuclease enzyme.

RESULTS: Analysis of FGFR4 Gly388Arg polymorphism revealed that the frequency of heterozygous (GA) mutation as well as the mutant allele $(A)$ was significantly higher in cases compared to control subjects with $p<0.001$ and 0.002 , respectively. The mutant genotypes were more prevalent at older age, aggressive clinical stage, bone marrow involvement, anemia, and thrombocytopenia at presentation. The mean of overall survival and the event free survival of our NHL patients were shorter in the mutant genotypes with $p=0.049$ and 0.017 , respectively.
\end{abstract}

CONCLUSION: This study provides evidence that FGFR4 Gly388Arg polymorphism confers a genetic susceptibility to NHL among Egyptians and has a poor prognostic impact.

\section{Introduction}

Non-Hodgkin lymphomas (NHLs) are a heterogynous group of lymphoproliferative malignancies with different presenting features, clinical course, and a response to the treatment. $\mathrm{B}$ lymphocytes represent $86 \%$ of origin of $\mathrm{NHL}$, while $14 \%$ arises from $\mathrm{T}$ lymphocytes or natural killer (NK) cells [1]. Among the many subtypes of $\mathrm{NHL}$, diffuse large $\mathrm{B}$ cell lymphoma (DLBCL) is the major subtype. It accounts for $24 \%$ of $\mathrm{NHL}$ new cases [2], [3] Follicular lymphoma (FL) is the second most common [4] while small lymphocytic leukemia (SLL) represents $7 \%$ of the NHL new cases [5].

Worldwide incidence of NHL revealed to be the most common malignancy; the tenth in males and the twelfth in females [6], with a high mortality as estimated deaths were 248,724 in 2018 [7]. Lymphoma in Egypt is the fourth most frequent tumor in adults. NHL assembly $76.6 \%$ with incidence rates are $16.3 / 100,000$ person [8]. In 2018, NHL is the third most common cancer in Egyptian males (8.2\%) as well as among females $(7.2 \%)$ with $7.3 \%$ deaths for both [9].

The etiologies of most lymphomas remain understood; however, altered immunological function and genetic susceptibility are assumed to play a crucial role in pathogenesis of lymphomas [10]. There is a high evidence that angiogenesis plays a key role in lymphoid malignancies. Expression of angiogenic factors such as vascular endothelial growth factor (VEGF) and basic fibroblast growth factor (bFGF) corresponds with the clinical features in lymphoma, and their level may act as prognostic markers for assessing the response to the treatment and recurrence [11].

Fibroblast growth factor receptors (FGFRs) are trans-membrane receptors; consist of four structurally related proteins (FGFR1-4). They belong to the family of tyrosine kinase receptors (RTKs). FGFR1-4 expressed differentially in various cell types involved in signaling through interactions with FGFs [11], [12]. 
FGFRs are incorporated in the regulation of several important biological activities, including cell metabolism, migration, angiogenesis, proliferation, differentiation, and survival [13].

FGFs stimulate angiogenesis through mitogen activated protein kinase (MAPK) activation and protein kinase $C(P K C)$ activation by stimulating endothelial cell proliferation, driving extracellular matrix degradation, changing intercellular adhesion by affecting cadherins, and altering integrin expression. Consequently, several pharmaceutical companies are developing highly potent FGFR tyrosine kinase inhibitors (TKIs), which are selective over VEGF receptors (VEGFRs) [14]

FGFR4 is present on the lymphocytes. Mutations of FGFR4 may lead to the imbalance of the FGF-FGFR system with subsequent angiogenesis [11]. FGFR4 Gly388Arg single nucleotide polymorphism (SNP) (rs351855) leads to change in a glycine residue to an arginine within the trans-membrane domain associated with disease progression and poor prognosis in many tumor types, as colon, breast, prostate, head and neck, soft tissue sarcomas, melanoma, and lung cancer [15], [16]. FGFR4 Gly388Arg is found to be correlated with increased susceptibility and poor prognosis of NHL in Chinese population [11].

The aim of this work was to investigate the relationship of FGFR4 Gly388Arg to susceptibility and prognosis of $\mathrm{B}-\mathrm{NHL}$ in the Egyptian population to identify some issues of genetic basis in relation to one of the most common cancer in our population to use it as a target point in the treatment in the future researches.

\section{Patients and Methods}

The present study was conducted on 75 adult Egyptian patients with newly diagnosed B-NHL with exclusion treatment received or double malignancies cases. Patients were selected from the department of Medical Oncology, National Cancer institute $(\mathrm{NCl})$ as well Haematology Outpatient Clinic, Faculty of Medicine, Cairo University in the period from year 2014 to 2015 with 5 years follow-up. Diagnosis was done by histopathology and immunohistochemistry according to the WHO classification of hematological malignancies. One hundred age-, gender-, and racematched healthy volunteers were included in the study as a control group.

Patients were subjected to full history taking, clinical examination, performance status assessment, routine laboratory work up of lymphoma including; complete blood picture, liver and kidney function tests, serum lactate dehydrogenase (LDH), cytological examination of any effusion, cerebrospinal fluid (CSF) cytology (if needed), and bone marrow examination (aspirate/biopsy) for staging.

The study was approved by the Faculty of Medicine, Cairo University ethical committee on April 2014 with approval number (I-420414). It was conducted in concordance with Declaration of Helsinki (ethical principles for medical research involving human subjects). A written informed consent was obtained from each participant.

\section{Sample collection}

Three to five millimeters of venous blood were collected on ethylene diamine tetra-acetic acid (EDTA) by sterile venepuncture using a sterile vacutainer tube. Samples were either stored in the same vacutainer at $-20^{\circ} \mathrm{C}$ or used directly within $24 \mathrm{~h}$ for DNA extraction.

\section{Identification of FGFR4 polymorphism Gly388 Arg genotypes}

DNA extraction was performed using QIAamp DNA Blood Mini Kit (Cat. No. 51104), Qiagen, Germany. Primers were provided by Thermo scientific. The forward primer sequence was: 5'GACCGCAGCAGCGCCCGAGGCCAG-3', and the reverse was: 5'- AGAGGGAAGAGGGAGAGCTTCTG -3 '. Polymerase Chain Reaction (PCR) was performed in a total volume of $25 \mu \mathrm{l}$ containing $12.5 \mu \mathrm{l}$ of DreamTaq PCR Master Mix (2X) (Cat. No. K1071- Thermo scientific), $5.5 \mu \mathrm{l}$ Nuclease-free water, $1 \mu \mathrm{l}$ of each primer, and $5 \mu$ lof Genomic extracted DNA.

PCR performed as the thermo-cycler program was conducted by initial denaturation at $95^{\circ} \mathrm{C}$ for $5 \mathrm{~min}$, followed by 35 cycles at $94^{\circ} \mathrm{C}$ for $30 \mathrm{~s}, 68^{\circ} \mathrm{C}$ for $30 \mathrm{~s}$, $72^{\circ} \mathrm{C}$ for $45 \mathrm{~s}$, and final elongation at $72^{\circ} \mathrm{C}$ for $5 \mathrm{~min}$.

After amplification, the PCR products (168 bp) were digested with Fast Digest BstNI restriction endoneuclease enzyme (Cat. No.: FD0554, Thermo Scientific): According to the manufacturer's protocols. Visualization of the restricted fragments by ethidium bromide stained agarose gel electrophoresis. Two fragments of 82 and $27 \mathrm{bp}$ characterized the mutant A allele, whereas a single visible band of $109 \mathrm{bp}$ was observed for the wild $\mathrm{G}$ allele with additional fragments of 22 and 37 bp presents in both genotypes (Figure 1).

\section{Statistical methods}

Data were analyzed using IBM SPSS advanced statistics version 22 (SPSS Inc., Chicago, IL). Numerical data were expressed as a mean and standard deviation or a median and range as appropriate, qualitative data were expressed by frequency and percentage. Chi-square test or Fisher's exact test was used to examine the relation between qualitative variables. For quantitative data, a comparison between two groups was done using either 
Student's t-test or Mann-Whitney test (non-parametric t-test) for not normally distributed data. Odds ratio (OR) with its $95 \%$ confidence interval $(\mathrm{Cl})$ was used for risk estimation. All tests were two-tailed. Survival rates of NHL patients were analyzed using Kaplan-Meier method and Log Rank Test. $p \leq 0.05$ was considered significant.

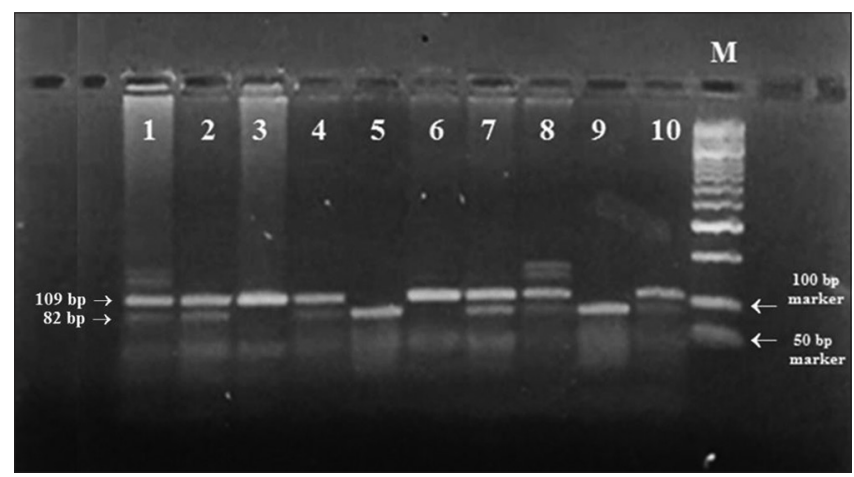

Figure 1: Identification of fibroblast growth factor receptor 4 polymorphism Gly388Arg genotypes by gel

\section{Results}

\section{Demographic data}

This study included 36 (48\%) male and 39 (52\%) female Egyptian patients. Their ages ranged between 17 and 79 years with a mean of $47.3 \pm 16.2$ years. Fifty-five (73.3\%) patients were $<60$ years and $20(26.7 \%)$ were $\geq 60$ years. The control group included 56 males $(56 \%)$ and 44 females (44\%). Their ages ranged between 18 and 77 years with a mean of $43.8 \pm 13.6$ years. The patients and controls were age and gender matched ( $p=0.133,0.294$, respectively) as well race matched.

According to histological classification of our $\mathrm{NHL}$ patients, they were classified into $53(70.7 \%)$ DLBCL, 13 (17.3\%) FL, and 9 (12\%) SLL cases.

Regarding DLBCL patients, they were $26(49.1 \%)$ males and $27(50.9 \%)$ females. Their ages ranged between 18 and 76 years with a mean of $48.1 \pm$ 15 years, $39(73.6 \%)$ were $<60$ years, and $14(26.4 \%)$ were $\geq 60$ years. FL cases were $6(46.2 \%)$ males and seven $(53.8 \%)$ females, $11(84.6 \%)$ were $<60$ years, and $2(15.4 \%)$ were $>60$ years alongside the age ranged between 17 and 79 years with a mean of $39 \pm$ 19.6 years. SLL participants were $4(44.4 \%)$ males and $5(55.6 \%)$ females. Their age range was between 38 and 79 years with a mean \pm SD of $54.7 \pm 14.5$ years to be divided into $5(55.6 \%)$ patients $<60$ years and $4(44.4 \%)$ cases $>60$ years old.

\section{Clinical criteria and treatment regimen}

In our NHL patients, 28 (37.3\%) patients presented with B-symptoms in the form of fever and/ or night sweats and/or weight loss. Lymphoma origin was nodal in $53(70.7 \%)$ patients and extra-nodal in $22(29.3 \%)$ patients. Extra-nodal involvement was present in $43(57.3 \%)$ patients to be $<2$ sites in 64 $(85.3 \%)$ patients while $\geq 2$ sites in $11(14.7 \%)$ patients. Bone marrow involvement was present in $20(26.7 \%)$ patients. Splenomegaly, hepatomegaly, mediastinal disease, and CNS involvement were noticed in 34 (45.3\%), 31 (41.3\%), $16(21.3 \%)$, and 2 (2.7\%) patients, respectively.

Nineteen (25.3\%) patients were of Stages I and II according to Ann Arbor scoring system [17] while $56(74.7 \%)$ ones were Stages III and IV. Fortyfive $(60 \%)$ cases were score $<2$ of Eastern Cooperative Oncology Group (ECOG) performance status [18] while $30(40 \%)$ patients were $\geq 2$. Regarding the International Prognostic Index (IPI) scoring system [19]; 44 (58.7\%) patients were low/intermediate low risk (1 and 2) and $31(41.3 \%)$ of them were intermediate high/high risk (3 and 4). Treatment regimen [20] was chemotherapy, radiotherapy, combined chemotherapy and radiotherapy or chemotherapy with antiCD20 monoclonal antibody (mAb) drugs in 32 (42.1\%), 2 (2.6\%), 4 (5.3\%), and 37 $(48.7 \%)$, respectively.

Regarding DLBCL patients; B-symptoms were conferred in $21(39.6 \%)$ patients. Nodal lymphoma origin was detected in $33(62.3 \%)$ patients while extranodal origin was found in $20(37.7 \%)$ patients. Extranodal involvement was observed in $32(60.4 \%)$ patients classified into $<2$ sites in $43(81.1 \%)$ patients and $\geq 2$ in $10(18.9 \%)$ patients. Bone marrow infiltration was in 12 (22.6\%) patients. Splenomegaly and hepatomegaly were present in $22(41.5 \%), 22$ (41.5\%), while mediastinal disease and CNS involvement were emerged in 13 $(24.5 \%)$ and 2 (3.8\%) patients independently.

On the other hand, $12(22.6 \%)$ patients were designated as Ann Arbor Stages I and II together with $41(77.4 \%)$ cases were rated as Stages III and IV. Performance status was found to be $<2$ in 29 (54.7\%) patients as well $\geq 2$ in $24(45.3 \%)$ patients. IPI revealed that $27(50.9 \%)$ patients were low/intermediate low risk (1 and 2) while $26(49.1 \%)$ were intermediate high/high risk (3 and 4). Treatment regimen [20] was chemotherapy in $17(32.1 \%)$, radiotherapy in $1(1.9 \%)$, and combined chemotherapy and radiotherapy in $2(3.8 \%)$ while antiCD20 mAb drugs were added to chemotherapy in $33(62.3 \%)$ of DLBCL patients.

FL cases presented with B-symptoms in 3 $(23.1 \%)$ patients. All patients were of nodal lymphoma origin. Extra-nodal involvement of $<2$ sites was recognized in $5(38.5 \%)$ patients with no involvement of $\geq 2$ sites. Bone marrow affection, splenomegaly, hepatomegaly, mediastinal disease, and CNS involvement were observed in $4(30.8 \%), 6(46.2 \%), 4$ $(30.8 \%)$, and $3(23.1 \%)$ patients, respectively.

Four (30.8\%) patients were Ann Arbor Stages I and II and 9 (69.2\%) cases were of Stages 
III and IV with $9(69.2 \%)$ patients were of score $<2$ of performance status and $4(30.8 \%)$ were of score $\geq 2$. Low/intermediate low risk (1 and 2) of IPI was found in $12(92.3 \%)$ patients while intermediate high/high risk (3 and 4 ) was in only one $(7.7 \%)$ case. Nine $(69.2 \%)$ patients received chemotherapy alone while 2 (15.4\%) received combined chemotherapy and radiotherapy as well $2(15.4 \%)$ received chemotherapy with antiCD20 mAb drugs [20].

In SLL, B-symptoms were present in 4 (44.4\%) patients. Nodal lymphoma origin was detected in 7 $(77.8 \%)$ patients while extra-nodal origin was remarked in $2(22.2 \%)$ patients. Extra-nodal involvement was observed in $6(66.7 \%)$ patients which categorized into $<2$ sites in $8(88.9 \%)$ and $\geq 2$ sites in $1(11.1 \%)$ patient only. On the other hand, 4 (44.4\%) patients showed bone marrow infiltration. Splenomegaly was present in $6(66.7 \%)$ patients while hepatomegaly in $5(55.6 \%)$ of patients. Mediastinal disease and CNS involvement were absent in SLL patients group.

Three (33.3\%) patients were of Ann Arbor Stages I and II while $6(66.7 \%)$ were of Stages III and IV. Performance status of score $<2$ and $\geq 2$ was discerned in $7(77.8 \%)$ and $2(22.2 \%)$ patients, respectively. IPI was calculated to be low/intermediate low risk (1 and 2) in 5 (55.6\%) patients and intermediate high/high risk (3 and 4 ) was in the other $4(44.4 \%)$ patients. Treatment protocol [20] was declared to be chemotherapy, radiotherapy, combined chemotherapy, and radiotherapy or chemotherapy with antiCD20 mAb drugs in $6(66.7 \%), 1(11.1 \%), 0(0 \%)$, and $2(22.2 \%)$, respectively.

\section{Laboratory parameters of routine investigations}

In our NHL cases, the hemoglobin level $(\mathrm{Hb})$ ranged between 7.1 and $15.7 \mathrm{~g} / \mathrm{dL}$ with a median value of $11.8 \mathrm{~g} / \mathrm{dL}$. The median value and the range of the total leukocyte count (TLC) were $7.9 \times 10^{3} / \mathrm{uL}$ and $\left(1.4-151 \times 10^{3} / \mathrm{uL}\right)$ while for the platelets count (PLTs) were $213 \times 10^{3} / \mathrm{uL}$ and $\left(29-678 \times 10^{3} / \mathrm{uL}\right)$, respectively. The range and median of LDH level were (105-2219 IU/L) and 258 IU/L independently. Thirty-eight (50.7\%) patients had high LDH levels ( $\geq 247 \mathrm{IU} / \mathrm{L})$ while 37 $(49.3 \%)$ cases had normal LDH levels ( $\leq 247$ IU/L).

For DLBCL patients, the ranges of $\mathrm{Hb}$, TLC, and PLTs were (7.6-15.5 g/dL), (1.80-14.8 × 103/uL), and $\left(29-678 \times 10^{3} / \mathrm{uL}\right)$ with a median value of $11.7 \mathrm{~g} /$ $\mathrm{dL}, 7.8 \times 10^{3} / \mathrm{uL}$, and $235 \times 10^{3} / \mathrm{uL}$, respectively. LDH level ranged between 105 and 2219 IU/L with a median value of $298 \mathrm{IU} / \mathrm{L}$. High LDH levels were found in 23 (43.4\%) patients while normal LDH levels were present in $30(56.6 \%)$ cases.

Regarding FL participants, the median value of $\mathrm{Hb}, \mathrm{TLC}$, and PLTs was $12.9 \mathrm{~g} / \mathrm{dL}, 6.60 \times 10^{3} / \mathrm{uL}$, and $221 \times 10^{3} / \mathrm{uL}$ independently. Each of them was ranged between (8.7-15.7 g/dL), (2.5-13.7 × 103/uL), and (150-346 $\left.\times 10^{3} / \mathrm{uL}\right)$, respectively. LDH level was ranged between 119 and $645 \mathrm{IU} / \mathrm{L}$ with a median value of $205 \mathrm{IU} / \mathrm{L}$. High and normal LDH levels were found in $3(23.1 \%)$ and $10(76.9 \%)$ patients, respectively.

SLL group showed the median value and range of LDH as $262 \mathrm{IU} / \mathrm{L}$ and (120-1099 IU/L) independently with normal LDH in 4 (44.4\%) patients while high LDH was found in $5(55.6 \%)$ ones. The median values of $\mathrm{Hb}, \mathrm{TLC}$, and PLTs were $11.4 \mathrm{~g} / \mathrm{dL}, 18.2 \times 10^{3} / \mathrm{uL}$, and $128 \times 10^{3} / \mathrm{uL}$ and their ranges were $(7.1-12.9 \mathrm{~g} / \mathrm{dL})$, $\left(1.4-151 \times 10^{3} / \mathrm{uL}\right)$, and $\left(38-166 \times 10^{3} / \mathrm{uL}\right)$, respectively.

\section{Genotyping of FGFR4 Gly388Arg polymorphism}

The mutant genotypes $(G A+A A)$ conferred an increased risk to NHL as well as to their subtypes; SLL, FL, and DLBL (OR and 95\% Cl: 3.317 [1.700-6.472]; 2.839 [1.363-5.914]; 3.429 [1.037-11.332]; and 8.000 [1.839-34.793]), respectively. Similarly, the mutant allele A was found to be a risk factor for NHL, DLBCL, and SLL (OR [95\% Cl]: 2.401 [1.364-4.227], 2.263 [1.219-4.203], and 3.667 [1.259-10.676], respectively) (Tables 1 and 2).

Table 1: Genotyping of FGFR4 polymorphism Gly388Arg among NHL cases and controls

\begin{tabular}{|c|c|c|c|c|c|c|}
\hline Genotypes & $\begin{array}{l}\text { Controls } \\
(n=100)(\%)\end{array}$ & $\begin{array}{l}\text { NHL patients } \\
(n=75) n(\%)\end{array}$ & $p$ value ${ }^{*}$ & OR & $95 \% \mathrm{Cl}$ & \\
\hline GG & $80(80)$ & $41(54.7)$ & --- & Ref. & --- & --- \\
\hline GA & $16(16)$ & $31(41.3)$ & $<0.001^{*}$ & 3.780 & 1.857 & 7.698 \\
\hline AA & $4(4)$ & $3(4)$ & 0.629 & 1.463 & 0.313 & 6.851 \\
\hline $\mathrm{GA}$ and $\mathrm{AA}$ & $20(20)$ & $34(45.3)$ & $<0.001^{*}$ & 3.317 & 1.700 & 6.472 \\
\hline $\mathrm{G}$ allele & 88.0 & 75.3 & $0.002^{*}$ & 2.401 & 1.364 & 4.227 \\
\hline A allele & 12.0 & 24.7 & & & & \\
\hline
\end{tabular}

\section{Association between genotypes of FGFR4 Gly388Arg polymorphism, demographic, clinical, and laboratory data of NHL patients}

In NHL cases, the mutant genotypes (GA + $A A)$ were more frequently encountered than the wild genotype in cases $\geq 60$ years old compared to cases $<60$ years old $(p=0.039)$. The mutant genotypes were more frequently encountered in cases with aggressive clinical stage (III and IV) and with bone marrow involvement ( $p=0.054$ and 0.039 , respectively)

No statistically significant difference was noticed between $\mathrm{NHL}$ patients with wild and mutant genotypes regarding their gender, the presence of B-symptoms at presentation, lymphoma origin, extranodal involvement, number of extranodal sites, splenomegaly, hepatomegaly, clinical staging, performance status, international prognostic index, mediastinal disease, CNS involvement, or histopathological types (Table 3).

The $\mathrm{Hb}$ and PLTs were significantly lower in the mutant genotypes compared to the wild genotype $(p=0.010$ and 0.007 , respectively). No statistically significant difference was noticed between NHL patients 
Table 2: Genotyping of FGFR4 polymorphism Gly388Arg among subtypes of NHL and controls

\begin{tabular}{|c|c|c|c|c|c|c|c|c|c|c|c|c|c|c|c|}
\hline Genotypes & $\begin{array}{l}\text { DLBCL patients } \\
(n=53)(\%)\end{array}$ & OR & $95 \% \mathrm{Cl}$ & & p value ${ }^{*}$ & $\begin{array}{l}\text { FL patients } \\
(\mathrm{n}=13) \mathrm{n}(\%)\end{array}$ & OR & $95 \% \mathrm{Cl}$ & & $p$ value ${ }^{*}$ & $\begin{array}{l}\text { SLL patients }(\mathrm{n}=9) \\
\mathrm{n}(\%)\end{array}$ & OR & $95 \% \mathrm{Cl}$ & & $p$ value ${ }^{*}$ \\
\hline$\overline{G G}$ & 31 (58.5) & Ref. & --- & --- & --- & $7(53.8)$ & Ref. & --- & $-\ldots$ & --- & $3 / 9$ (33.3) & Ref. & --- & --- & --- \\
\hline GA & $19(35.8)$ & 3.065 & 1.400 & 6.710 & $0.005^{*}$ & $6(46.2)$ & --- & --- & -- & --- & $6 / 9(66.7)$ & --- & --- & --- & --- \\
\hline AA & $3(5.7)$ & 1.935 & 0.409 & 9.149 & 0.405 & $0(0)$ & --- & --- & --- & --- & $0 / 9(0)$ & --- & --- & --- & --- \\
\hline GA and $A A$ & $22(41.5)$ & 2.839 & 1.363 & 5.914 & $0.005^{*}$ & $6(46.2)$ & 3.429 & 1.037 & 11.332 & $0.035^{*}$ & $6 / 9(66.7)$ & 8.000 & 1.839 & 34.793 & $0.002^{*}$ \\
\hline $\mathrm{G}$ allele & 76.4 & 2.263 & 1.219 & 4.203 & $0.009^{*}$ & 76.9 & 2.200 & 0.804 & 6.023 & 0.117 & 66.7 & 3.667 & 1.259 & 10.676 & $0.012^{*}$ \\
\hline A allele & 23.6 & & & & & 23.1 & & & & & 33.3 & & & & \\
\hline
\end{tabular}

with wild and mutant genotypes regarding their serum LDH and TLC (Table 3).

Table 3: Association between genotypes of FGFR4 polymorphism Gly388Arg, demographic, clinical, and laboratory data of NHL patients

\begin{tabular}{|c|c|c|c|}
\hline $\mathrm{NHL}$ cases characters & Wild $(n=41) \%$ & Mutant $(\mathrm{n}=34) \%$ & $p$ value \\
\hline \multicolumn{4}{|l|}{ Age } \\
\hline$\leq 60$ years & $34(61.8)$ & $21(38.2)$ & \multirow[t]{2}{*}{$0.039^{*}$} \\
\hline$\geq 60$ years & $7(35)$ & $13(65)$ & \\
\hline \multicolumn{4}{|l|}{ Gender } \\
\hline Male & $23(63.9)$ & $13(36.1)$ & \multirow[t]{2}{*}{0.123} \\
\hline Female & $18(46.2)$ & $21(53.8)$ & \\
\hline B-symptoms & $14(50)$ & $14(50)$ & 0.531 \\
\hline \multicolumn{4}{|l|}{ Lymphoma origin } \\
\hline Nodal & $28(52.8)$ & $25(47.2)$ & \multirow[t]{2}{*}{0.620} \\
\hline Extra-nodal & $13(59.1)$ & $9(40.9)$ & \\
\hline Extra-nodal involvement & $22(51.2)$ & $21(48.8)$ & 0.480 \\
\hline \multicolumn{4}{|l|}{ Number of extra-nodal sites } \\
\hline$\leq 2$ & $36(56.3)$ & $28(43.8)$ & \multirow{2}{*}{0.506} \\
\hline$\geq 2$ & $5(45.5)$ & $6(54.5)$ & \\
\hline Bone marrow involvement & $7(35)$ & $13(65)$ & $0.039^{*}$ \\
\hline Splenomegaly & $18(52.9)$ & $16(47.1)$ & 0.785 \\
\hline Hepatomegaly & $14(45.2)$ & $17(54.8)$ & 0.165 \\
\hline Mediastinal disease & $9(56.3)$ & $7(43.8)$ & 0.886 \\
\hline CNS involvement & $2(100)$ & $0(0)$ & --- \\
\hline \multicolumn{4}{|l|}{ Clinical stage } \\
\hline I and II & $14(73.7)$ & $5(26.3)$ & \multirow[t]{2}{*}{$0.054^{*}$} \\
\hline III and IV & $27(48.2)$ & $29(51.8)$ & \\
\hline \multicolumn{4}{|l|}{ PS } \\
\hline Score $\leq 2$ & $27(60)$ & $18(40)$ & \multirow[t]{2}{*}{0.256} \\
\hline Score $\geq 2$ & $14(46.7)$ & $16(53.3)$ & \\
\hline \multicolumn{4}{|l|}{ IPI risk groups } \\
\hline Low/Intermediate low (1 and 2 ) & $27(61.4)$ & $17(38.6)$ & \multirow[t]{2}{*}{0.165} \\
\hline Intermediate high/high ( 3 and 4 ) & $14(45.2)$ & $17(54.8)$ & \\
\hline \multicolumn{4}{|l|}{ Treatment } \\
\hline Chemotherapy & $14(34.1)$ & $18(52.9)$ & \multirow{4}{*}{0.240} \\
\hline Radiotherapy & $2(4.9)$ & $0(0)$ & \\
\hline Chemotherapy+radiotherapy & $3(7.3)$ & $1(2.9)$ & \\
\hline Chemotherapy+antiCD20 mAb & $22(53.7)$ & $15(44.1)$ & \\
\hline \multicolumn{4}{|l|}{$\mathrm{Hb} g / \mathrm{dL}$} \\
\hline Median & 12.6 & 11.0 & \multirow[t]{2}{*}{$0.010^{*}$} \\
\hline Range & $8.0-15.7$ & $7.1-15.0$ & \\
\hline \multicolumn{4}{|l|}{ TLC $\times 10^{3} / \mathrm{uL}$} \\
\hline Median & 8.0 & 7.6 & \multirow[t]{2}{*}{0.682} \\
\hline Range & $2.4-18.2$ & $1.4-151.0$ & \\
\hline \multicolumn{4}{|l|}{$\mathrm{PLTs} \times 10^{3} / \mathrm{uL}$} \\
\hline Median & 242 & 180 & \multirow[t]{2}{*}{$0.007^{*}$} \\
\hline Range & $97-678$ & $29-564$ & \\
\hline \multicolumn{4}{|l|}{ LDH IU/L } \\
\hline Median & 238 & 284.5 & \multirow[t]{2}{*}{0.380} \\
\hline Range & $115-980$ & $105-2219$ & \\
\hline
\end{tabular}

is significant if $\leq 0.05, \mathrm{CNS}$ : Centa Nervous System, $\mathrm{Hb}$ : Hemoglobin, IPI: International Prognostic Index, LDH: Lactate dehydrogenase, mAb: Monoclonal antibody, NHL: Non-Hodgkin lymphoma, PLTs: Platelets, PS: Performance status, TLC: Total leukocyte count.

\section{FGFR4 genotyping and prognosis of $\mathrm{NHL}$}

Over a follow-up period of 5 years; the number of deaths within GG, GA, and AA genotypes was 16 (39\%), $19(61.3 \%)$, and 2 (66.7\%), respectively. The mean of overall survival (OS) was significantly lower in mutant genotypes (GA + AA): 30.806 months compared to be 42.674 months in the wild GG genotype with ( $p=$ 0.049) (Figure 2).

The mean of the event free survival (EFS) in patients with GG, GA, and AA genotypes was 38.6, 23.6, and 29.97 months, respectively, which was a statistically significant difference $(p=0.047)$. The mean EFS was lower in mutant $(G A+A A)$ genotypes
(24.2 months) compared to 38.6 months in wild (GG) genotype $(p=0.017)$ (Figure 3$)$.



Figure 2: Overall survival of Non-Hodgkin lymphomas patients according to genotypes of fibroblast growth factor receptor 4 rs351855G/A polymorphism

\section{Discussion}

NHLs include different subtypes of lymphoproliferative disorders with a variety of presentations and prognosis [21]. NHL is considered one of the most common types of all cancers in world as well as Egypt [6], [8]. The underling mechanisms of NHL are still questionable with many contributing factors [10].



Figure 3: Event free survival of Non-Hodgkin lymphomas patients according to genotypes of fibroblast growth factor receptor 4 rs351855G/A polymorphism 
Angiogenesis including FGF-FGFR system disturbance is considered an important key in development and progression of lymphomas. The FGFR4 rs351855G/A (Gly388Arg) was detected in various tumors as prostate, pancreatic, renal cell carcinomas as well as NHL as risk and poor prognostic factor [16]. Our study confirmed at that this SNP is risk factor and a poor prognostic indicator in NHL Egyptian patients.

The present work revealed that the presence of heterozygous mutation GA conferred a 3.7 fold increased risk for $\mathrm{NHL}$ susceptibility $(\mathrm{OR}=3.780,95 \%$ $\mathrm{Cl}=1.857-7.698)$, the presence of the mutant allele (A) carried a higher risk for $\mathrm{NHL}$ incidence $(\mathrm{OR}=2.401$, $95 \% \mathrm{Cl}=1.364-4.227$ ).

In consistence with our results, Cha et al. (2014) [22] investigated 412 patients with $\mathrm{NHL}$ and 476 healthy controls for FGFR4 (Gly388Arg) polymorphism by PCRRestriction Fragment Length polymorphism (PCRRFLP). To confirm the genotyping results, more than $10 \%$ of PCR-amplified DNA samples were examined by DNA sequencing. Results between PCR and DNA sequencing analysis were $100 \%$ concordant. They reported that the frequencies of FGFR4 (Gly388Arg) in patients group for the heterozygous mutant genotype (GA) and homozygous mutant genotype (AA) were $45.9 \%$ and $28.1 \%$, respectively, compared to those of controls $50.4 \%$ and $15.8 \%$, respectively. These results showed that the frequencies of homozygous mutant genotype $(A A)$ were significantly higher in patients than in controls $(p<0.0001, \mathrm{OR}=2.12,95 \% \mathrm{Cl}=1.99-3.48)$.

Similarly, Gao et al. (2014) [11] investigated 421 patients with $\mathrm{NHL}$ and 486 healthy controls for FGFR4 (Gly388Arg) polymorphism by PCR-RFLP. More than $5 \%$ of PCR-amplified DNA samples were examined by DNA sequencing. Results between PCR and DNA sequencing analysis were $100 \%$ concordant. They found that the frequencies of FGFR4 (Gly388Arg) in patients group for the heterozygous mutant genotype (GA) and homozygous mutant genotype (AA) were $44.9 \%$ and $27.3 \%$, respectively, compared to those of controls that were $49.4 \%$ and $15.4 \%$, respectively. These results showed that the frequencies of homozygous mutant genotype (AA) were significantly higher in patients than in controls $(p<0.001, O R=2.02$, 95\% Cl=1.91-3.23).

In the present study, the allelic frequencies for $\mathrm{G}$ and $\mathrm{A}$ alleles in NHL patients were $75.3 \%$ and $24.7 \%$, respectively, compared to those of controls $88 \%$ and $12 \%$, respectively. The presence of the mutant allele $(A)$ conferred a 2.4 fold increased risk for $\mathrm{NHL}$ susceptibility $(\mathrm{P}=0.002, \mathrm{OR}=2.401,95 \% \mathrm{Cl}=1.364-4.227)$.

In agreement with our findings, Cha et al. (2014) [22] found that the allelic frequencies for $G$ and $A$ alleles in patients were $48.9 \%$ and $51.1 \%$, respectively, compared to those of controls $59 \%$ and $41 \%$, respectively. Thus, the frequency of the mutant
(A) allele was higher in patients than in controls. This was statistically significant $(p<0.0001, \mathrm{OR}=1.45,95 \%$ $\mathrm{Cl}=1.21-1.88)$

Our results are also consistent with Gao et al. (2014) [11] regarding the allelic frequencies, as they found that frequencies for $G$ and $A$ alleles in patients were $50.2 \%$ and $49.8 \%$, respectively, compared to those of controls $59.9 \%$ and $40.1 \%$, respectively. Thus, the mutant $(A)$ allele was significantly higher in patients than in controls $(p<0.001$, OR $=1.33,95 \%$ $\mathrm{Cl}=1.16-1.75)$.

Furthermore, we analyzed the frequencies of FGFR4 (Gly388Arg) polymorphism genotypes in different histopathological subtypes compared to controls. We are first to demonstrate these relations.

The heterozygous mutant genotype (GA) was overrepresented compared to the wild genotype (GG), (P=0.005, OR = 3.065, 95\% Cl = 1.400-6.710). The mutant genotypes ( $G A$ and $A A$ ) frequency was significantly higher in DLBCL subjects $(P=0.005, O R=$ $2.839,95 \% \mathrm{Cl}=1.363-5.914$, respectively).

Similarly, the mutant allele (A) frequency was significantly higher in DLBCL patients compared to controls $(p=0.009$, OR $=2.263,95 \% \mathrm{Cl}=1.219$ 4.203). The mutant genotypes ( $G A+A A)$ frequency in FL cases were significantly higher compared to controls $(p=0.035$, OR $=3.429,95 \% \mathrm{Cl}=1.037-11.332)$.

In SLL, the genotype distribution could not be assessed statistically due to the small group numbers; however, the frequency of the mutant allele $(A)$ was significantly higher in SLL patients compared to controls $(\mathrm{P}=0.012, \mathrm{OR}=3.667,95 \% \mathrm{Cl}=1.259-10.676)$.

Our result demonstrated the prevalence of mutant genotypes in patients older than 60 years $(p=$ $0.039)$, advanced clinical stage $(p=0.054)$, with bone marrow involvement $(p=0.039)$, lower hemoglobin $(p=$ $0.01)$, and platelet count at diagnosis ( $p=0.007)$. These findings point to a possible association of that SNP with poor prognosis. No statistically significant difference regarding lymphoma origin could be detected as found in Gao et al. (2014) [11].

FGFR4 is expressed on different cell types including lymphoid cells. It is one of receptor tyrosine kinases (RTK). RTKs activation institutes a series of internal reactions through kinase activation involved in cellular proliferation and survival [22]. FGFR4 Arg388 allele decreases receptor stability with persistent receptor stimulation. Therefore, it may aggravate carcinogenesis by augmenting its growth, mobilization, and angiogenesis [23].

Ulaganathan and Ullrich (2016) demonstrated that FGFR4 Gly388Arg disrupts transmembrane portion of the receptor with subsequent exposure of membrane-proximal binding site of cytoplasmic STAT3 Y390-(P)XXQ393. This stimulates phosphorylation of STAT3 with increasing cell proliferation [24]. 
However, the constitutional behavior of FGFR4 rs351855G/A is uncertain. Many proofs indicate its implication in cancer susceptibility. In vitro, a study in breast cancer demonstrated that the cells which carry the variant of $\mathrm{rs} 351855 \mathrm{G} / \mathrm{A}$ showed an increase motility than those of wild type. In prostatic cancer, transfection of cDNA carrying the variant form was found to increase the violation features of prostatic epithelial cell line [16].

Our results demonstrated shorter OS and EFS in mutant genotypes (GA+AA) compared to wild genotype. This was consistent with Cha et al. (2014) [22], who found shorter OS in AA genotype compared to GA + GG genotypes with $p=0.002$ as well as in the study performed by Gao et al. (2014) [11] with $p<0.001$. This suggests the impact of FGFR4 Gly388Arg on prognosis of NHL.

Tateno et al. (2011) [25] showed that the effect on FGFR4 Gly388Arg constituted mainly disruption of receptor/ ligand affinity, decaying, and interactions. In another issue, FGFR4 Gly388Arg showed acceleration in the phosphorylation of STAT in mitochondria in pituitary carcinogenesis with a subsequent enhancing in the cell growth [16].

FGFR4 Arg (388) allele was found to be higher in germ cell lines of many tumors of cancer patients of poor prognosis [26]. It affects cancer severity; lymph nodes affection, deterioration of its clinical stage, and survival of various tumor such as prostatic cancer and lung adenocarcinoma [27]. This SNP appeared to play an important role in carcinogenesis as well as in prognosis and may act in tumors as a marker of screening and a target of therapy by future further researches. As the exact process by which that variant enhanced $\mathrm{NHL}$ probability is still unexplained, so FGFR4 Gly388Arg is our focus of research.

The authors faced some obstacles due to the lack of a financial support to do the confirmatory sequencing of the results although it was done in the previous studies in different ethnic groups. This study still contributes an important issue in the understanding of the association between FGFR4 polymorphisms and $\mathrm{NHL}$ in our population.

\section{Conclusion}

Our study suggests that FGFR4 polymorphism rs351855 (Gly388Arg) plays a significant role in NHL risk in our population. The patients with mutant genotypes are at higher risk to have an advanced clinical stage, bone marrow involvement, anemia, and thrombocytopenia at presentation as well as shorter OS and EFS.

\section{References}

1. Swerdlow SH, Campo E, Harris NL, Jaffe ES, Pileri SA, Stein H, et al. WHO Classification of Tumours of Haematopoietic and Lymphoid Tissues. $4^{\text {th }}$ ed., Vol. 2. Geneva, Switzerland: World Health Organization; 2017. p. 585.

2. Siegel R, Miller K, Jemal A. Cancer statistics, 2019. CA Cancer J Clin. 2019;69(1):7-34.

PMid:30620402

3. Liu Y, Barta SK. Diffuse large B-cell lymphoma: 2019 update on diagnosis, risk stratification, and treatment. Am J Hematol. 2019;94(5):604-16. https://doi.org/10.1002/ajh.25460 PMid:30859597

4. Freedman A. Follicular lymphoma: 2018 update on diagnosis and management. Am J Hematol. 2018;93(2):296-305. https:// doi.org/10.1002/ajh.24937।

PMid:29314206

5. Clinical Practice Guidelines in Oncology. Chronic lymphocytic leukemia/small lymphocytic lymphoma. J Natl Compr Canc Netw. 2015;13(3):326-62.

PMid:25736010

6. MirandaFilho A, Pineros M, Znaor A, MarcosGragera $R$, SteliarovaFoucher E, Bray F. Global patterns and trends in the incidence of non-Hodgkin lymphoma. Cancer Causes Control 2019;30(5):10091. https://doi.org/10.1007/s10552-019-01155-5

7. Bray F, Ferlay J, Soerjomataram I, Siegel RL, Torre LA, Jema A. GLOBOCAN estimates of incidence and mortality worldwide for 36 cancers in 185 countries: Global cancer statistics. CA Cancer J Clin. 2018; 68(6): 394-424. https://doi.org/10.3322/ caac. 21492

8. Elsammak A. Clinical usefulness of PET-CT in staging evaluation of treatment response and restaging of thoracic lymphoma. Egypt J Radiol Nuclear Med. 2017;48(4):1073-81. https://doi.org/10.1016/j.ejrnm.2017.04.005

9. Ferlay J, Colombet M, Soerjomataram I, Mathers C, Parkin DM Piñeros $\mathrm{M}$, et al. Estimating the global cancer incidence and mortality in 2018: GLOBOCAN sources and methods. Int J Cancer. 2019;144(8):1941-53. https://doi.org/10.1002/ijc.31937 PMid:30350310

10. Cheng S, Li J, Liu W, Liu Ch, Su L, Liu X, et al. LTA + 252A $>G$ polymorphism is associated with risk of nasal NK/T -cell lymphoma in a Chinese population: A case-control study. BMC Cancer. 2015;15:480. https://doi.org/10.1186/ s12885-015-1506-4

11. Gao L, Feng Z, Li Q, Li L, Chen L, Xiao T. Fibroblast growth factor receptor 4 polymorphism is associated with increased risk and poor prognosis of non-Hodgkin's lymphoma. Tumor Biol. 2014;35(4):2997-3002. https://doi.org/10.1007/ s13277-013-1386-7 PMid:24248544

12. Hallinan N, Finn S, Cuffe S, Rafee S, O'Byrne K, Gately K. Targeting the fibroblast growth factor receptor family in cancer. Cancer Treat Rev. 2016;46:51-62. https://doi.org/10.1016/j. ctrv.2016.03.015 PMid:27109926

13. Chen J, Hao P, Zheng T, Zhang Y. miR-628 reduces prostate cancer proliferation and invasion via the FGFR2 signaling pathway. Exp Ther Med. 2019;18(2):1005-12. https://doi. org/10.3892/etm.2019.7682

PMid:31316598

14. Kang X, Lin Z, Xu M, Pan J, Wang Z. Deciphering role of FGFR signalling pathway in pancreatic cancer. Cell Prolif. 2019;52(3):e12605. https://doi.org/10.1111/cpr.12605 PMid:30945363 
15. Ou L, He X, Liu N, Song Y, Li J, Gao L, et al. Sialylation of FGFR1 by ST6Gal-I overexpression contributes to ovarian cancer cell migration and chemoresistance. Mol Med Report. 2020;21(3):1449-60. https://doi.org/10.3892/mmr.2020.10951 PMid:32016470

16. Xiong SW, Ma J, Feng F, Fu W, Shu SR, Ma T, et al. Functional FGFR4 Gly388Arg polymorphism contributes to cancer susceptibility: Evidence from meta-analysis. Oncotarget. 2017;8(15):25300-9. https://doi.org/10.18632/oncotarget.15811 PMid:28445975

17. Cheson BD, Fisher RI, Barrington SF, Cavalli F, Schwartz LH, Zucca E, et al. Recommendations for initial evaluation, staging, and response assessment of Hodgkin and NonHodgkin lymphoma: The Lugano classification. J Clin Oncol. 2014;32(27):3059-68. https://doi.org/10.1200/jco.2013.54.8800 PMid:25113753

18. Mei Hsien CC, Wan Azman WA, Yusof M, Ho GF, Krupat E. Discrepancy in patient-rated and oncologist-rated performance status on depression and anxiety in cancer: A prospective study protocol. BMJ Open. 2012;2(5):e001799. https://doi. org/10.1136/bmjopen-2012-001799

\section{PMid:23035016}

19. Adams HJ, de Klerk JM, Fijnheer R, Heggelman BG, Dubois SV Nievelstein RA, et al. Does the presence of tumor-induced cortical bone destruction at CT have any prognostic value in newly diagnosed diffuse large B-cell lymphoma? Skeletal Radiol. 2015;44(5):687-94. https://doi.org/10.1007/s00256-015-2102-z PMid:25662178

20. Treating Non Hodgkin lymphoma-American cancer society cancer.org | 1.800.227.2345. 2018; P1-49. Available from: https://www.cancer.org/content/dam/CRC/PDF/Public/8720.00. pdf.

21. Wróbel T, Mazur G, Dzietczenia J, Gębura K, Kuliczkowski K, Bogunia-Kubik K. VEGF and bFGF gene polymorphisms in patients with non-Hodgkin's lymphoma. Biomed Res Int. 2013;2013:59813. https://doi.org/10.1155/2013/159813 PMid:23998120

22. Cha Z, Zang Y, Guo H, Gu H, Tu X, Song H, et al. Fibroblast growth factor receptor 4 polymorphisms and the prognosis of non-Hodgkin lymphoma. Mol Biol Rep. 2014;41(2):1165-70. https://doi.org/10.1007/s11033-013-2963-y

PMid:24381107

23. Tang S, Hao Y, Yuan Y, Liu R, Chen Q. Role of fibroblast growth factor receptor 4 in cancer. Cancer Sci. 2018;109(10):3024-31. https://doi.org/10.1111/cas.13759

PMid:30070748

24. Ulaganathan VK, Ullrich A. Membrane-proximal binding of STAT3 revealed by cancer-associated receptor variants. Mol Cell Oncol. 2016;3(3):e1145176. https://doi.org/10.1080/23723 556.2016 .1145176 PMid:27314095

25. Tateno T, Asa SL, Zheng L, Mayr T, Ullrich A, Ezzat S. The FGFR4-G388R polymorphism promotes mitochondrial STAT3 serine phosphorylation to facilitate pituitary growth hormone cell tumorigenesis. PLoS Genet. 2011;7(12):e1002400. https://doi. org/10.1371/journal.pgen.1002400

PMid:22174695

26. Spinola M, Leoni V, Pignatiello C, Conti B, Ravagnani $F$, Pastorino U, et al. Functional FGFR4 Gly388Arg polymorphism predicts prognosis in lung adenocarcinoma patients. J Clin Oncol. 2005;23(29):7307-11. https://doi.org/10.1200/ jco.2005.17.350

PMid: 16061909

27. Chou CH, Hsieh MJ, Chuang CY, Lin JT, Yeh CM, Tseng PY, et al. Functional FGFR4 Gly388Arg polymorphism contributes to oral squamous cell carcinoma susceptibility. Oncotarget. 2017;8(56):96225-38. https://doi.org/10.18632/oncotarget.21958 PMid:29221201 